time course of the ACT over this period of heparin removal. The ACT after completion of this treatment was 160 seconds, whereas the baseline ACT before CPB was 192 seconds. Other coagulation studies, however, showed a persistent coagulopathy that was corrected over the next 4 hours with infusion of fresh frozen plasma and cryoprecipitate. She was also treated with epsilon aminocaproic acid to correct abnormal fibrinolysis. The chest tube output was 300 to $400 \mathrm{ml} / \mathrm{hr}$ for the first 4 hours after heparin removal but diminished to an insignificant level, and she did well thereafter.

No alternatives to protamine for heparin reversal are currently available. Although platelet factor 4 has been shown to be an effective neutralizer of heparin, ${ }^{2}$ it is in the early stages of investigation and will likely not be available in the near future. The Heparin Removal Device uses a plasmapheresis filter that is widely used clinically but has a resin added to the plasma compartment that binds and removes heparin. This approach to heparin removal has great potential merit as an alternative to protamine. It awaits a phase 1 clinical trial after FDA review and approval as an investigational device.

\section{REFERENCES}

1. Vertrees RA, Zwischenberger JB, McRea JC, Kurusz M, Conti VR. Reversal of anticoagulation without protamine. ASAIO J 1994;40:M560-4.

2. Bernabei AF, Gikakis N, Malone TE, Niewiarowski $\mathrm{S}$, Edmunds LH. Platelet factor 4-an alternative to protamine. J Thorac CARdiovasc Surg [In press].

\title{
PRELIMINARY RESULTS OF DEFEROXAMINE AND L1 TREATMENT OF SPINAL CORD ISCHEMIA
}

David G. Reuter, PhD, MD, Willis A. Tacker, Jr., MD, PhD, Charles F. Babbs, MD, PhD, Stephen F. Badylak, DVM, PhD, MD, William D. Voorhees III, PhD, and Peter E. Konrad, PhD, MD, West Lafayette, Ind.

Vascular surgery necessitating aortic occlusion produces spinal cord ischemia, which can subsequently lead to paraplegia. Previous studies suggest lipid-rich central nervous system tissue is sensitive to amplification of ischemic injury by free radical mechanisms that lead to lipid peroxidation. ${ }^{1}$ Drugs that prevent free radical production and thus lipid peroxidation offer promise as a way to protect the spinal cord during periods of ischemia. ${ }^{2}$ The agents deferoxamine and 1,2-dimethyl-3-hydroxypyrid-4one (L1) are postulated to inhibit iron-catalyzed lipid peroxidation. Deferoxamine is a water-soluble iron chelator that has been shown to attenuate reperfusion injury in isolated rat hearts. ${ }^{3} \mathrm{~L} 1$ is a novel lipid-soluble iron chelator that has been shown to effectively chelate excess iron in a study of chronic transfusional iron overload (i.e., $\beta$-thalassaemia). ${ }^{4}$ Our goal was to use these two drugs to test the hypothesis that iron plays an important role in the pathophysiologic reactions leading to spinal cord damage attendant to ischemia and reperfusion.

Our preliminary study was performed in two stages. We

From the Hillenbrand Biomedical Engineering Center, Purdue University, West Lafayette, IN 47907-1293.

Supported by grant HL-36712 from the National Heart, Lung, and Blood Institute, U.S. Public Health Service, Bethesda Md.

J Thorac Cardiovasc Surg 1995;109:1017-9

Copyright (C) 1995 by Mosby-Year Book, Inc.

$0022-5223 / 95 \$ 3.00+0 \quad \mathbf{1 2 / 8 / 5 8 6 0 9}$ first developed a model of spinal cord ischemia that produced paraplegia in a majority of dogs..$^{5}$ The second phase of our study used the initial series of dogs as historical controls to determine if treatment with deferoxamine or L1 would significantly improve the neurologic outcome or histopathologic damage.

In the second phase of our study, 13 mongrel dogs were sequentially divided into a deferoxamine-treated group $(n=5)$ and an L1 group $(n=8)$. The dogs were pretreated with atropine sulfate $0.4 \mathrm{mg} / \mathrm{kg}$ subcutaneously and acetylpromazine $0.22 \mathrm{mg} / \mathrm{kg}$ subcutaneously and were anesthetized with thiopental 9 to $13 \mathrm{mg} / \mathrm{kg}$ intravenously. After intubation, nitrous oxide was delivered by inhalation in a 1:2 ratio with oxygen, and anesthesia was maintained by repeated intravenous boluses of thiopental. A balloon catheter was inflated in the aorta just distal to the left subclavian artery to achieve spinal cord ischemia, and the duration of ischemia was determined by the amplitude reduction of the mean evoked potential signal, as it was in our initial study. The details of the evoked potential stimulaton, histopathologic scoring, regional blood flow studies, and neurologic assessment are identical to phase 1 of the study. ${ }^{5}$ In the first group of dogs, deferoxamine 25 $\mathrm{mg} / \mathrm{kg}$ was infused intravenously over a 20 -minute period, starting 30 minutes before aortic occlusion. Another 25 $\mathrm{mg} / \mathrm{kg}$ dose of deferoxamine was administered over a 20 -minute period beginning 10 minutes before reperfusion. In the other group, L1 $25 \mathrm{mg} / \mathrm{kg}$ was administered intravenously according to the same protocol. All animals received humane care in compliance with the "Principles 


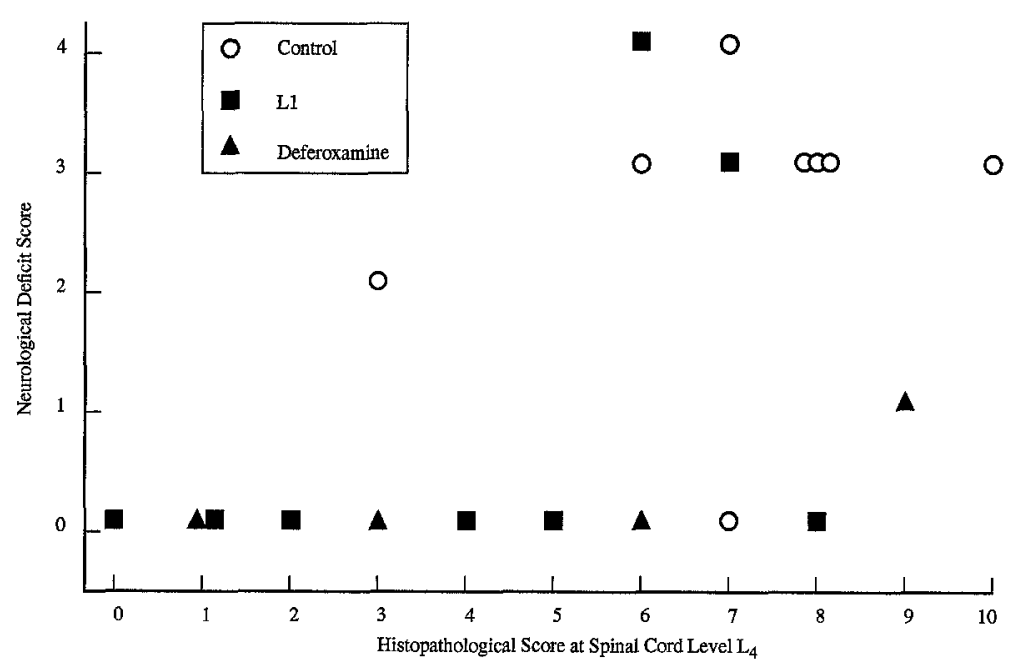

Fig. 1. Correlation of neurologic outcome and histopathologic damage for the historical control, deferoxamine- and L1-treated groups of dogs. On the ordinate, the neurologic outcome is represented semiquantitatively with different combinations of increasing neurologic deficits. For this axis, the numeric value was obtained by summing the muscle tone and withdrawal reflex results each on a scale of 0 to 2 , where normal $=0$, hyperreflexia/hyporeflexia and slow withdrawal reflex $=1$, and spasticity/atonia and areflexia $=2$. The maximal possible score $=4$; the minimum score $=0$. On the abscissa, the histopathologic damage at level of the fourth lumbar vertebra $\left(L_{4}\right)$ is reflected by the damage score (higher number $=$ more severe damage), which was determined by our previously published criteria. ${ }^{5}$ All dogs with a neurologic deficit score of 2 to 4 could not walk. Dogs with a deficit score of 0 or 1 could walk. Therefore, note that all but one of the dogs in the control group were paralyzed, whereas only two dogs from the treatment group (L1) could not walk.

of Laboratory Animal Care" formulated by the National Society for Medical Research and the "Guide for the Care and Use of Laboratory Animals" prepared by the National Academy of Sciences (NIH Publication No. 80-23, revised 1978). The study was approved by the Purdue University Animal Care and Use Committee.

The mean durations of aortic occlusion in the control, deferoxamine, and L1 groups were $36.1 \pm 8.5,28.6 \pm 9.2$, and $32.6 \pm 11.2$, respectively. The correlation between neurologic outcome and histopathologic damage for the three groups of dogs is summarized in Fig. 1. In the nonintervention group, seven of the eight dogs had moderate to severe motor deficits. In the deferoxaminetreated group, all five dogs had significantly fewer motor deficits at 24 hours than the control group ( $p=0.005$ by Fisher's exact test) as evidenced by absence of muscle spasticity and no brisk withdrawal to a pinch of the interdigital web. Of the eight dogs in the L1-treated group, six demonstrated normal muscle tone and a brisk withdrawal to a pinch of the interdigital web of the hind limb. There was a significant difference in the neurologic outcome of dogs in the L1-treated group compared with the control group ( $p=0.05$ by Fisher's exact test). Comparison of histopathologic results from all three groups revealed that there was no significant difference in the extent of microglial cell infiltration and vacuolation of the lumbar gray matter. However, in contrast to the historical controls, the integrity of the neurons in both the deferoxamine and L1 groups appeared to be preserved.
Although some swelling and satellitosis of the lower motor neurons were present, fewer pyknotic and necrotic neurons were observed. The exception to this finding was the two dogs in the L1-treated group, which had significant motor deficits. They were found to have severe neuronal damage characterized by neuronophagia and pyknosis at the level of the fourth lumbar vertebra.

The initial model of spinal cord ischemia we developed produced an $88 \%$ incidence of paraplegia in a control group of dogs and was thus used to test different pharmacologic interventions. The study presented was designed to evaluate the extent to which iron plays a role in ischemia/reperfusion injury of the spinal cord. The preliminary results of our study suggest that treatment with either deferoxamine or $\mathrm{L} 1$ will reduce cellular and functional deficits. In addition, the fact that amelioration of damage was achieved with a water-soluble iron chelator suggests that perhaps it is less crucial that a drug cross the blood-brain barrier and more crucial that the iron chelator be in contact with the central nervous system microvasculature. A prospective, randomized, double blind study is recommended to further elucidate the effectiveness of both deferoxamine and L1 in treating spinal cord ischemia.

\section{REFERENCES}

1. Coles JC, Ahmed SN, Mehta HU, Kaufmann JCE. Role of free radical scavenger in protection of spinal 
cord during ischemia. Ann Thorac Surg 1986;41: 551-6.

2. Hall ED, Yonkers PA, Andrus PK, Cox JW, Anderson DK. Biochemistry and pharmacology of lipid antioxidants in acute brain and spinal cord injury. $\mathrm{J}$ Neurotrauma 1992;9(Suppl 2):S425-42.

3. Reddy BR, Kloner RA, Przylenk K. Early treatment with deferoxamine limits myocardial ischemic/reperfusion injury. Free Radic Biol Med 1989;7:45-52.
4. Kontoghiorghes GJ, Jackson MJ, Lunec J. In vitro screening of iron chelators using models of free radical damage. Free Radic Res Commun 1986;2:11524.

5. Reuter DG, Tacker WA, Badylak SF, Voorhees WD III, Konrad PE. Correlation of motor-evoked potential response to ischemic spinal cord damage. $J$ THORAC CARDIOVASC SURG 1992;104:262-72.

\title{
RELIEF OF COMPLEX LEFT VENTRICULAR OUTFLOW TRACT OBSTRUCTION WITH PULMONARY AUTOGRAFTS
}

\author{
Ulrik Hvass, MD, Didier Chatel, MD, José Calliani, MD, and Yves Pansard, MD, Paris, France
}

Pulmonary autografts harvested with a larger than usual amount of anterior ventricular infundibulum $(2$ to $3 \mathrm{~cm}$ instead of approximately $1 \mathrm{~cm}$ ) may be used for complete relief of complex left ventricular outflow tract obstructions. The autograft obtained renders prosthetic septal reconstruction unnecessary, as has been reported by Daenen and Gewillig. ${ }^{1}$

We used this technique in two patients, 5 and 6 years of age, who had a diminutive aortic anulus and diffuse subaortic obstructions. One patient had had a transaortic resection 3 years earlier.

The general lines of the operation are those of aortic root replacement with pulmonary autografts. ${ }^{2}$ The pulmonary artery is transected at the bifurcation, and then the pulmonary ventricular infundibulum is incised transversely about $3 \mathrm{~cm}$ from the pulmonary valve anulus. Excision of the pulmonary root is completed, reducing this distance laterally to the usual 4 to $6 \mathrm{~mm}$. Exposure and enlargement of the interventricular septum is much more comfortable than in the Konno operation. ${ }^{3}$ Starting at the intercoronary commissure, the septal incision is continued into the infundibular septum. Because the pulmonary autograft is already larger than the diminutive aortic anulus, the septal opening may be extended 3 to $4 \mathrm{~cm}$, allowing for an efficient enlargement of the left ventricular outflow tract. The septum is augmented with the autograft's larger than usual anterior muscular flap, similar to the

From Hopital Bichat, Chirurgie Cardio Vasculaire, Paris, France. J Thorac Cardiovasc Surg 1995;109:1019

Copyright (C) 1995 by Mosby-Year Book, Inc. $0022-5223 / 95 \$ 3.00+0 \quad \mathbf{1 2 / 8 / 6 1 2 8 1}$ technique reported for aortoventriculoplasties with aortic allografts retaining the anterior mitral leaflet. ${ }^{4}$

Postoperative echocardiograms (follow-up of 6 and 2 months) with Doppler recordings show efficient relief of obstruction with low residuel gradients and less than trivial central regurgitation.

The technique has two advantages: First, no prosthetic material is used; a Dacron patch in contact with the autograft exposes leaffets to abrasion. ${ }^{5}$ Second, the technique is relatively simple to do.

\section{REFERENCES}

1. Daenen W, Gewillig M. Extended aortic root replacement with pulmonary autografts. Eur J Cardiothorac Surg 1993;7:42-6.

2. Matsuki O, Okita Y, Almeida RS, et al. Two decades of experience with aortic valve replacement with pulmonary autograft. J THORAC CARDIOVASC SuRG 1988;95: 705-11.

3. Konno S, Imai Y, Lida Y, Nakajima M, Tatsuno K. A new method for prosthetic valve replacement in congenital aortic stenosis associated with hypoplasia of the aortic valve ring. J Thorac Cardiovasc Surg 1975;70: 909-17.

4. McKowen RL, Campbell DN, Woelfiel GF, Wiggins JW, Clarke DR. Extended aortic root replacement with aortic allografts. J THORAC CARDIOVASC SURG 1987;93: 366-74.

5. Elkins RC, Knott-Craig CJ, Ward KE, McCue C, Lane MM. Pulmonary autograft in children: realized growth potential. Ann Thorac Surg 1994;57:1387-94. 